\title{
Entrepreneurial Orientation and Firm Performance: Evidence from
} Argentina

\author{
Enrique Diaz ${ }^{1}, \&$ Luca Sensini ${ }^{2}$ \\ ${ }^{1}$ BeLab - Business Economics Laboratory, Buenos Aires, Argentina \\ ${ }^{2}$ Department of Management and Innovation System, University of Salerno, Italy \\ Correspondence: Enrique Diaz, BeLab - Business Economics Laboratory, Buenos Aires, Argentina.
}

Received: June 22, 2020

doi:10.5539/ibr.v13n8p47
Accepted: July 14, 2020

Online Published: July 21, 2020

URL: https://doi.org/10.5539/ibr.v13n8p47

\begin{abstract}
This document aims to study the role played by the five dimensions of entrepreneurial orientation on corporate performance. To test our hypotheses, we used a sample of companies headquartered in Argentina. To collect the data, we used a questionnaire that was sent by e-mail to the owner and/or manager of the companies. At the end of the survey, 214 Argentine companies (21.4\% of the sample) completed the questionnaire. The sampling was carried out with a stratified random approach to improve the efficiency of the estimates and ensure the representativeness of the extracted sample. To assess the reliability of the results, quantitative statistical tools were used. The analysis results show that not all variables have a significant influence on performance. In particular, three dimensions of the EO (innovation, proactivity, and risk) have a significant and positive influence on the performance of companies. Conversely, competitive aggressiveness and autonomy do not have a significant impact on performance or they are not relevant.
\end{abstract}

Keywords: entrepreneurial orientation, performance, strategy, innovation, Argentina

\section{Introduction}

Starting from the seminal paper of Miller (1983), subsequently developed and expanded by Covin and Slevin (1989) and Lumpkin and Dess (1996), the concept of entrepreneurial orientation (EO) has been much debated by literature (Covin et al., 2006; Rauch et al., 2009; Wales et al., 2011; Cavusgil and Knight, 2015; Gupta and Dutta, 2018; Ferreira et al., 2019). In this study, we use the concept of multidimensional entrepreneurial orientation based on its five elements: risk-taking, proactivity, innovation, competitive aggressiveness, and autonomy.

Although this approach to the study of entrepreneurial orientation has already been developed from the literature, the results are often conflicting (Stetz et al., 2000; Kreiser et al., 2002; Wiklund and Shepherd, 2005; Lechner and Gudmundsson, 2014; Engelen et al., 2015). Furthermore, as demonstrated by some scholars, different cultural contexts can produce different results (Lee and Peterson, 2000; Kreiser et al., 2010). Therefore, this paper aims to expand the literature on the subject, studying the effect of entrepreneurial orientation on company performance in Argentina, a context not yet explored by literature (Shirokova et al.,2016; Ferreira et al., 2019). In this perspective, the specific cultural and social environment of a country can influence the different dimensions of the EO, making some aspects prevail over others. (Lumpkin and Dess, 1996). Therefore, the national context can moderate the effect of entrepreneurial orientation on company performance, acting as a moderator.

Following an approach suggested by the literature (Covin et al., 2006; Lumpkin and Dess, 1996), this study uses a multidimensional construct of the EO, where the influence of each dimension is connected to the performance of the company and can have a different impact on the latter. To this aim, we assume that there is a positive relationship between each dimension of the $\mathrm{EO}$ and business performance.

To test our hypotheses, we used a sample of companies headquartered in Argentina. In line with other empirical research (Kreiser et al., 2002, Rigtering et al., 2017), a questionnaire that was sent by e-mail to the owner and/or manager of the companies was used to collect data. Initially, 287 companies agreed to participate in the research (28.7\% of the sample). At the end of the survey, 214 Argentine companies (21.4\% of the sample) completed the questionnaire.

The sampling was carried out on the whole reference population, following a stratified random approach. This 
setting made it possible to improve the efficiency of the estimates and to guarantee the representativeness of the extracted sample, also reducing the variability of the estimates with respect to the use of a random sample. Considering the high territorial extension of Argentina, we used a geographical and economic criterion to guarantee the representativeness of the sample. To evaluate the reliability of the results, quantitative statistical tools were used. In particular, we used generalized regression analysis as it provides more reliable estimates.

The results of the analysis show that not all variables have a significant influence on performance. In particular, three dimensions of the EO (innovation, proactivity, and risk) have a significant and positive influence on the performance companies. Conversely, competitive aggressiveness and autonomy do not have an impact on performance or they are not relevant.

The paper is organized as follows. Section 2 analyzes the literature on the topic and develops the research hypotheses. The research design and the methods of sample formation are highlighted in section 3 . Section 4 shows the results of the research and the last section reports the concluding remarks.

\section{Literature Review and Research Hypoteses}

The concept of EO, initially introduced by Mintzberg (1973), was subsequently better specified by Miller (1983), who stressed that the entrepreneurial approach aims to innovate and aggressively enter new markets, accepting the risks associated with the search for new opportunities. Miller's seminal approach (1983) was later taken up and developed by Covin and Slevin (1989) who introduced a 9-item measuring scale, that was widely used by the literature (Kropp et al., 2006; Rauch et al., 2009; Wales et al., 2013; Rigtering et al., 2017; Hernandez-Perlines et al., 2019).

Over the years, literature has developed several approaches to address the problem of entrepreneurial orientation. Among the different approaches, there are two dominant perspectives. The first perspective is based on a one-dimensional approach (Covin and Slevin, 1989, Knight, 1997) which considers the EO as a unitary construct characterized by the simultaneous presence of risk-taking, innovation, and proactivity. In this perspective, the EO can only be analyzed as a whole and therefore it does not make sense to consider every single part that composes it (Gupta and Gupta, 2015).

The second perspective is based on a multidimensional approach, which considers the EO as a construct characterized by numerous independent elements: risk, innovation, proactivity, competitive aggressiveness, and autonomy (Lumpkin and Dess, 1996). This approach qualifies the entrepreneur on the basis of the different presence of each of the characterizing elements (Lumpkin and Dess, 1996; Hughes and Morgan, 2007; Polites et al., 2012).

Despite the common matrix of the two perspectives, the two approaches are distinct and can lead to conflicting results on the qualification of the entrepreneurial orientation (Covin and Wales, 2019).

Although the debate on the advantages and disadvantages of the two approaches is still very heated (Rauch et al., 2009, Rosenbusch et al., 2013, Gupta and Dutta, 2018; Wales et al., 2013; Anderson et al., 2015; Rigtering et al., 2017), in this document we use the multidimensional perspective. According to this approach, the five dimensions that characterize the entrepreneurial orientation are: risk-taking, proactivity, innovation, competitive aggressiveness, and autonomy and can be briefly defined as below. Risk-takings requires the ability to take bold actions in conditions of uncertainty (Kraus et al., 2012, Lumpkin and Dess, 1996, Rigtering et al., 2017).

Proactivity implies an active attitude towards competition and customers, which requires the ability to launch new products/services and predict and/or stimulate customer needs (Covin and Slevin, 1989; Lumpkin and Dess, 1996; Rigtering et al., 2017).

Innovation requires a creative path to support the birth, development, and testing of new ideas that can promote the survival and development of the company (Miller and Friesen, 1983; Kropp et al., 2006; Chandra et al., 2009; De Jong and Freel, 2010; Covin et al., 2016).

Competitive aggressiveness is the combative attitude of a company aimed at increasing its market share and surpassing competitors (Lumpkin and Dess, 1996). Finally, independence indicates the freedom to act without external influences and the autonomy of employees in proposing and developing new ideas and new projects (Covin and Slevin, 1996).

In the context outlined, the relationship between EO and corporate performance has given rise to a broad debate in the literature. However, the results are discordant. On the one hand, some authors have suggested that companies with a strong presence of the five dimensions that characterize EO perform better than other companies (Wales et al., 2013; Filser et al., 2014; Saeed et al., 2014; Shirokova et al., 2016; Hernandez-Perlines, 
2018; Rauch et al., 2009; Covin and Slevin, 1991; Lumpkin and Dess, 2001; Wiklund and Shepherd, 2005). On the other hand, other studies have shown that the dimensions of the EO do not have a positive effect on corporate performance (Zainol and Ayadurai, 2011; Mahmood and Hanafi, 2013; Arshad et al., 2014; Ojewumi and Fagbenro, 2019). Finally, further studies have shown an inconclusive relationship, highlighting the moderating role that environmental variables can play (Arshad et al., 2014; Kosa et al., 2018).

In this latter regard, the literature has suggested that the reference context influences the entrepreneurial orientation and therefore the performance of the company (Miller, 1983; Covin and Slevin, 1989; Stetz et al., 2000; Lomberg et al., 2017). In this perspective, the company's behavior is mainly conditioned by the value system of the person responsible for the decision-making process, and therefore by the cultural and social values of its community (Huggins \& Thompson, 2014). Therefore, the behavior of companies is also conditioned by the institutional reference environment, and therefore by the system of rules present in a given context (Fayolle et al., 2010; Lee et al., 2011; Ma \& Todorovic, 2012; among others).

Consequently, the reference context can have an impact on entrepreneurial orientation and this impact varies according to the country analyzed (Kreiser et al., 2010; Lomberg et al., 2017).

In this perspective, the EO must be conceived as a multidimensional construct (Covin et al., 2006) in which the influence of each dimension is connected to the performance of the company and can be conditioned by contextual factors (Lumpkin \& Dess, 1996).

In the context outlined, in this document we agree with the literature which suggests a positive relationship between EO and performance, however recognizing that each dimension of EO will have a different impact on performance (Rigtering et al., 2017).

Therefore, our research hypotheses are as follows:

H1: proactivity and performance are positively correlated.

H2: risk-taking and performance are positively correlated

H3: innovation and performance are positively correlated.

H4: competitive aggressiveness and performance are positively correlated.

H5: autonomy and performance are positively correlated.

\section{Research Design and Sample}

The sample of our study is made up of companies headquartered in Argentina. For the collection of data, a questionnaire was sent by e-mail to the owner and/or manager of the companies.

The sampling was carried out in a probabilistic way on the whole reference population. Subsequently, in line with the literature (Cochran, 1977), we performed a stratified random sampling. This approach allowed to improve the efficiency of the estimates and to guarantee the representativeness of the extracted sample (Amendola et al., 2020). Furthermore, this approach has made it possible to reduce the variability of the estimates compared to the use of a random sample. To ensure the representativeness of the sample, the elements of interest were identified on the basis of a geographical and economic criterion.

From a geographical point of view, this approach has made it possible to consider the differences existing in a very vast territory such as Argentina. From an economic point of view, this approach has allowed us to consider that the behavior and strategies of companies are strongly influenced by the size of their organization.

The sample size was set to 1000 units, to ensure an error $|d| \leq 0.055$ with a probability of 0.95 based on the following:

$$
n=\frac{n_{0}}{1+\frac{n_{0}}{N}}
$$

where $\mathrm{N}$ is the population size and $\mathrm{n} 0$ is given by:

$$
n_{o}=\frac{z^{2}(0.975) p(1-p)}{\varepsilon^{2}}
$$

The $p$ level was set assuming a maximum level of variability, reached for $p=0.5$. The sample units belonging to each stratum were selected based on the incidence of each subgroup within the population. The questionnaire 
was initially tested on a small sample of companies to verify the quality of the structure. Based on what emerged from this first analysis, we improved the questionnaire to prevent the distortion of data and information (Rong and Wilkinson, 2011, Woodside, 2013). After the test phase, we sent an email to all companies explaining the purpose of the study and providing other general information. Overall, 287 companies agreed to participate in the research (28.7\% of the sample). Subsequently, we sent the questionnaire to all the companies that had joined. The structure of the questionnaire is modular and is divided into 3 sections. The first section contained general data about the company, the owner, and the manager. The second section included questions needed to measure the five dimensions of the EO and the firm's performance. Finally, the third section explored the perception of the reference context.

At the end of the survey, 214 Argentine companies (21.4\% of the sample) completed the questionnaire.

The questionnaire was prepared first in English and then translated into Spanish, using the reverse translation technique. To evaluate the reliability of the results, quantitative statistical tools were used.

In particular, we used generalized regression analysis as it provides more reliable estimates. The main results are highlighted in the next section and the regression model used in the present study is as follows:

FPERFit $=\beta 0+\beta 1 P R O+\beta 2 I N N+\beta 3 R T+\beta 4 C A+\beta 5 A U+$ eit.

Where:

FPERF, Firm Performance;

ß0, coefficient of the explanatory variable;

B1PRO, Proactiveness;

B2INN, Innovation;

B3RT, Risk-taking;

B4CA, Competitive Aggressiveness;

B5AU, Autonomy;

eit, Error term.

\section{Results and Discussion}

The main characteristics of the companies that participated in the research are highlighted in table 1 .

Table 1. General sample information

\begin{tabular}{llrr}
\hline & & $\mathrm{N}$. & $\%$ \\
\hline Sectors & Primary & 34 & 15.9 \\
& Industry & 138 & 64.5 \\
& Services & 42 & 19.6 \\
\hline Size & Small & 69 & 32.2 \\
& Medium & 118 & 55.2 \\
& Larger & 27 & 12.6 \\
\hline Age & $<25$ & 148 & 69.2 \\
& $>25$ & 66 & 30.8 \\
\hline Gender & Male & 168 & 78.5 \\
& Female & 46 & 21.5 \\
\hline Studies & No University & 151 & 70.6 \\
& University & 63 & 29.4 \\
\hline & & &
\end{tabular}

The sample is made up of a large prevalence of companies in the industrial sector (64.5\%) and small (32.2\%) and medium-sized enterprises (55.2\%). Most companies (69.2\%) have been founded for less than 25 years. The owner and/or manager are predominantly male $(78.5 \%)$ without a university degree $(70.6 \%)$.

The results of the descriptive statistics are shown in table 2. 
Table 2. Descriptive statistics

\begin{tabular}{lcccc}
\hline Variables & Mean & Median & Std. Dev. & Observations \\
\hline Risk-taking (RT) & 0.28 & 0.67 & 0.24 & 214 \\
Proactiveness (PRO) & 0.94 & 0.43 & 0.25 & 214 \\
Innovation (INN) & 0.06 & 0.87 & 0.47 & 214 \\
Competitive aggressiveness (CA) & 0.46 & 0.86 & 0.34 & 214 \\
Autonomy (AU) & 0.99 & 0.66 & 0.78 & 214 \\
Performance (PERF) & 0.71 & 0.66 & 0.67 & 214 \\
\hline
\end{tabular}

To test the reliability of the questionnaire and its internal consistency, we used Cronbach's alpha coefficient. The coefficient was equal to 0.77 , therefore the instrument used must be considered statistically reliable as it is greater than 0.7 .

To test the regression analysis we conducted collinearity tests for the possible presence of misleading results. The results highlight the absence of multicollinearity, as shown in table 3.

Consequently, it must be assumed that all variables are appropriate and fit well in the model.

Table 3. VIF Test

\begin{tabular}{ll}
\hline Variables & VIF \\
\hline Risk-taking & 1.09 \\
Proactiveness & 2.12 \\
Innovation & 2.28 \\
Competitive aggressiveness & 1.07 \\
Autonomy & 1.14 \\
Mean VIF & 1.54 \\
\hline
\end{tabular}

Table 4 highlights the correlation analysis of the variables considered in this study.

Table 4. Correlation Matrix

\begin{tabular}{lrrrrrr}
\hline Variables & PERF & RT & PRO & INN & CA & AU \\
\hline Performance & 1 & & & & & \\
Risk-taking & 0.561 & 1 & & & & \\
Proactiveness & 0.256 & 0.148 & 1 & & & \\
Innovation & 0.312 & -0.235 & 0.164 & 1 & & \\
Competitive aggressiveness & 0.134 & 0.236 & 0.731 & 0.059 & 1 & \\
Autonomy & 0.193 & 0.523 & 0.059 & 0.398 & 0.412 & 1 \\
\hline
\end{tabular}

The results show that the relationship between corporate performance and risk-taking is significant at 0.561 , the proactivity ratio is 0.256 , the innovation ratio is 0.312 , while the competitive aggressiveness ratio is 0.134 and the autonomy ratio is 0.193 .

To verify the validity of the regression model, we performed the checks highlighted in table 5 .

Table 5. Model Summary

\begin{tabular}{lr}
\hline Multiple R & 0.651 \\
R Square & 0.468 \\
Adjusted R Square & 0.416 \\
Heteroscedasticity test & 0.0712 \\
Observations & 214 \\
\hline
\end{tabular}

As is evident, the model is devoid of heteroscedasticity $(0.0712>0.05)$ and the data are normally distributed. The R square value is 0.468 , therefore the five dimensions analyzed were significant in $46.8 \%$ of cases.

Table 6 highlights the influence of relationships between the five dimensions of EO and corporate performance. 
Table 6. Regression Result

\begin{tabular}{lrr}
\hline Variables & Beta & P-value \\
\hline Risk-taking & 0.037 & 0.003 \\
Proactiveness & 0.131 & 0.009 \\
Innovation & 0.112 & 0.007 \\
Competitive aggressiveness & 0.019 & 0.482 \\
Autonomy & 0.273 & 0.000 \\
\hline
\end{tabular}

The highest coefficient is equal to 0.273 for autonomy, with a P-value equal to 0.000 . Proactivity has a positive beta of 0.121 , with a significance of 0.009 . The innovation has a positive coefficient of 0.112 and is significant at 0.007. Risk-taking has a positive coefficient of 0.037 and is significant at 0.003 . Finally, competitive aggressiveness has a beta of 0.019 and a p-value of 0.482 . Consequently, competitive aggressiveness is not significant for business performance.

Therefore, based on the analysis performed, hypotheses 1,2 , and 3 must be accepted, while hypotheses 4 and 5 cannot be accepted or are not significant.

\section{Concluding Remarks}

This paper aims to study the role played by the five dimensions of entrepreneurial orientation on the performance of Argentinian companies. In this perspective, we hypothesized a positive relationship between each dimension of the $\mathrm{EO}$ and business performance.

To test our hypotheses, we used a sample of companies headquartered in Argentina. To collect the data, we used a questionnaire that was sent by e-mail to the owner and/or manager of the companies. Initially, 287 companies agreed to participate in the research (28.7\% of the sample). At the end of the survey, 214 Argentine companies (21.4\% of the sample) completed the questionnaire.

The sampling was carried out on the whole reference population, following a stratified random approach to improve the efficiency of the estimates and ensure the representativeness of the extracted sample. Considering the high territorial extension of Argentina, we used a geographical and economic criterion to guarantee the representativeness of the sample.

To assess the reliability of the results, quantitative statistical tools were used.

The results of the analysis show that not all variables have a significant influence on performance. In particular, three dimensions of the EO (innovation, proactivity, and risk) have a significant and positive influence on the performance of companies. Therefore, hypotheses 1, 2, and 3 of this study must be accepted. Conversely, competitive aggressiveness and autonomy do not have an impact on performance or they are not relevant.

Therefore, given that not all dimensions of the EO have the same influence on performance, Argentinian companies should focus attention only on the relevant variables compatible with their objectives.

The results of this study may be useful for entrepreneurs to improve the elements of the EO that affect business performance. Furthermore, the results can provide useful indications to policy-makers on what factors to incentivize to encourage the birth and development of entrepreneurship. The results of this study have some limitations in that they focus on a limited set of variables. In addition, the small size of the sample can affect the results. Subsequent research could consider further variables, such as human capital and the context of reference, and consider a larger sample.

\section{Acknowledgments}

The authors would like to thank all BeLab researchers for their valuable help in processing the questionnaire data.

\section{Authorship contribution Statement}

Diaz E.: Data curation, Data Analysis, Results and Discussion, Concluding Remarks.

Sensini L.: Conceptualization, Methodology, Data Analysis, Results and Discussion; Concluding Remarks.

\section{References}

Amendola, A., Candila, V., Sensini, L., \& Storti, G. (2020). Corporate Governance, Investment, Profitability and Insolvency Risk: Evidence from Italy. Advances in Management and Applied Economics, 10(4), 185-202.

Anderson, B. S., Kreiser, P. M., Kuratko, D. F., Hornsby, J. S., \& Eshima Y. (2015). Reconceptualizing 
entrepreneurial orientation. Strategic Management Journal, 36(10), 1579-1596. https://doi.org/10.1002/smj.2298

Cavusgil, S. T., \& Knight, G. (2015). The born global firm: An entrepreneurial and capabilities perspective on early and rapid internationalization. Journal of International Business Studies, 46(1), 3-16. https://doi.org/10.1057/jibs.2014.62

Chandra, Y., Styles, C., \& Wilkinson, I. (2009). The recognition of first time international entrepreneurial opportunities: Evidence from firms in knowledge-based industries. International Marketing Review, 26(1), 30-61. https://doi.org/10.1108/02651330910933195

Cochran, W. G. (1977). Sampling Techniques. Wiley, New York.

Covin, J., \& Wales W. (2019). Crafting high-impact entrepreneurial orientation research: Some suggested guidelines. Entreprenership Theory and Practice, 43(1), 3-18. https://doi.org/10.1177/1042258718773181

Covin, J., \& Slevin, D. (1989), Strategic management of small firms in hostile and benign environments. Strategic Management Journal, 10(1), 75-87. https://doi.org/10.1002/smj.4250100107

Covin, J., Green, K., \& Slevin D. (2006). Strategic process effects on the entrepreneurial orientation-sales growth rate relationship. Entrepreneurship Theory and Practice, 30(1), 57-81. https://doi.org/10.1111/j.1540-6520.2006.00110.x

De Jong, J. P. J., \& Freel, M. (2010). Absorptive capacity and the reach of collaboration in high technology small firms. Research Policy, 39(1), 47-54. https://doi.org/10.1016/j.respol.2009.10.003

Engelen, A., Gupta, V., Strenger, L., \& Brettel, M. (2015). Entrepreneurial orientation, firm performance, and the moderating role of transformational leadership behaviors. Journal of Management, 41(4), 1069-1097. https://doi.org/10.1177/0149206312455244

Fayolle, A., Basso, O., \& Bouchard, V. (2010). Three levels of culture and firms' entrepreneurial orientation: A research agenda. Entrepreneurship \& Regional Development, 22(7-8), 707-730. https://doi.org/10.1080/08985620903233952

Ferreira, J. J., Fernandes, C. I., \& Kraus, S. (2019). Entrepreneurship research: Mapping intellectual structures and research trends. Review of Managerial Science, 13(1), 181-205. https://doi.org/10.1007/s11846-017-0242-3

Filser, M., Eggers, F., Kraus, S., \& Málovic, E. (2014). The effect of financial resource availability on entrepreneurial orientation, customer orientation and firm performance in an international context: An empirical analysis from Austria and Hungaria. Journal of East European Management Studies, 19(1), 7-30. https://doi.org/10.5771/0949-6181-2014-1-7

Gupta, V. K., \& Dutta, D. K. (2018). The rich legacy of Covin and Slevin (1989) and Lumpkin and Dess (1996): A constructive critical analysis of their deep impact on entrepreneurial orientation research. In Javadian, G, Gupta, V. K., \& Dutta, D. K. (Eds.), Foundational Research in Entrepreneurship Studies. New York: Palgrave Macmillan, pp. 155-178. https://doi.org/10.1007/978-3-319-73528-3_8

Gupta, V., \& Gupta, A. (2015). The concept of entrepreneurial orientation. Foundations and Trends® in Entrepreneurship, 11(2), 55-137. https://doi.org/10.1561/0300000054

Hernández-Perlines, F., Moreno-García, J., \& Yáñez-Araque B. (2019). The influence of socioemotional wealth in the entrepreneurial orientation of family businesses. International Entrepreneurship and Management Journal, 15(2), 523-544. https://doi.org/10.1007/s11365-019-00561-0

Huggins, R., \& Thompson, P. (2014). Culture, entrepreneurship and uneven development: A spatial analysis. Entrepreneurship \& Regional Development, 26, 9-10. https://doi.org/10.1080/08985626.2014.985740

Hughes, M., \& Morgan, R. E. (2007). Deconstructing the relationship between entrepreneurial orientation and business performance at the embryonic stage of firm growth. Industrial Marketing Management, 36(5), 651-661. https://doi.org/10.1016/j.indmarman.2006.04.003

Javadian, G., Gupta, V. K., Dutta, D. K., Guo, G. C., Osorta, A. E., Ozkazanc-Pan, B. (Eds.). (2018). Foundational research in entrepreneurship studies. Palgrave Macmillan, Cham, Switzerland, pp. 155-177.

Knight, G. A. (1997). Cross-cultural reliability and validity of a scale to measure firm entrepreneurial orientation. Journal of Business Venturing, 12(3), 213-225. https://doi.org/10.1016/S0883-9026(96)00065-1

Kreiser, P. M., Marino, L. D., \& Weaver, K. M. (2002). Assessing the psychometric properties of the 
entrepreneurial orientation scale: A multi-country analysis. Entrepreneurship Theory and Practice, 26(4), 71-94. https://doi.org/10.1177/104225870202600405

Kreiser, P. M., Marino, L. D., Dickson, P., \& Weaver, K. M. (2010). Cultural influences on entrepreneurial orientation: The impact of national culture on risk taking and proactiveness in SMEs. Entrepreneurship Theory and Practice, 34(5), 959-984. https://doi.org/10.1111/j.1540-6520.2010.00396.x

Kropp, F., Lindsay, N. J., \& Shoham, A. (2006). Entrepreneurial, market, and learning orientations and international entrepreneurial business venture performance in South African firms. International Marketing Review, 23(5), 504-523. https://doi.org/10.1108/02651330610703427

Lechner, C., \& Gudmundsson, S. V. (2014). Entrepreneurial orientation, firm strategy and small firm performance. International Small Business Journal, 32(1), 36-60. https://doi.org/10.1177/0266242612455034

Lee, S. M., \& Peterson S. J. (2000). Culture, entrepreneurial orientation, and global competitiveness. Journal of World Business, 35(4), 401-416. https://doi.org/10.1016/S1090-9516(00)00045-6

Lee, S., Lim, S., \& Pathak, R. (2011). Culture and entrepreneurial orientation: A multi-country study. International Entrepreneurship and Management Journal, 7(1), 1-15. https://doi.org/10.1007/s11365-009-0117-4

Lomberg, C., Urbig, D., Stöckmann, C., Marino, L. D., \& Dickson, P. H. (2017). Entrepreneurial orientation: The dimensions' shared effects in explaining firm performance. Entrepreneurship Theory and Practice, 41(6), 973-998. https://doi.org/10.1111/etap.12237

Lumpkin, G., \& Dess G. (1996). Clarifying the entrepreneurial orientation construct and linking it to performance. Academy of Management Review, 21(1), 135-172. https://doi.org/10.5465/amr.1996.9602161568

Ma, J., \& Todorovic, Z. W. (2012). Understanding the role of entrepreneurial quality and national culture on the economic development. International Journal of Entrepreneurship and Small Business, 16(3), 299-313. https://doi.org/10.1504/IJESB.2012.047437

Miller, D. (1983). The correlates of entrepreneurship in three types of firms. Management Science, 29(7), 770-791. https://doi.org/10.1287/mnsc.29.7.770

Miller, D., \& Friesen, P. H. (1983). Strategy-making and environment: The third link. Strategic Management Journal, 4(3), 221-235. https://doi.org/10.1002/smj.4250040304

Mintzberg, H. (1973). Strategy-making in three modes. California Management Review, 16(2), $44-53$. https://doi.org/10.2307/41164491

Polites, G. L., Roberts, N., \& Thatcher, J. (2012). Conceptualizing models using multidimensional constructs: A review and guidelines for their use. European Journal of Information Systems, 21(1), 22-48. https://doi.org/10.1057/ejis.2011.10

Rauch, A., Wiklund, J., Lumpkin, G., \& Frese, M. (2009). Entrepreneurial orientation and business performance: An assessment of past research and suggestions for the future. Entrepreneurship Theory and Practice, 33(3), 761-787. https://doi.org/10.1111/j.1540-6520.2009.00308.x

Rigtering, J. C., Eggers, F., Kraus, S., \& Chang, M. L. (2017). Entrepreneurial orientation, strategic planning and firm performance: The impact of national cultures. European Journal of International Management, 11, 301-324. https://doi.org/10.1504/EJIM.2017.083872

Rosenbusch, N., Rauch, A., \& Bausch, A. (2013). The mediating role of entrepreneurial orientation in the task environment-performance relationship: A meta-analysis. Journal of Management,39(3),633-659. https://doi.org/10.1177/0149206311425612

Saeed, S., Yousafzai, S. Y., \& Engelen, A. (2014). On cultural and macroeconomic contingencies of the entrepreneurial orientation-performance relationship. Entrepreneurship Theory and Practice, 38(2), 255-290. https://doi.org/10.1111/etap.12097

Shirokova, G., Bogatyreva, K., Beliaeva, T., \& Puffer, S. (2016). Entrepreneurial orientation and firm performance in different environmental settings: Contingency and configurational approaches. Journal of Small Business and Enterprise Development, 23(3), 703-727. https://doi.org/10.1108/JSBED-09-2015-0132

Stetz, P. E., Howell, R., Stewart, A., Blair, J. D., \& Fottler, M. D. (2000). Multidimensionality of entrepreneurial 
firm-level processes: Do the dimensions covary? Frontiers of Entrepreneurship Research.

Wales, W. J., Gupta, V. K., \& Mousa, F. T. (2013). Empirical research on entrepreneurial orientation: An assessment and suggestions for future research. International Small Business Journal, 31(4), 357-383. https://doi.org/10.1177/0266242611418261

Wales, W., Monsen, E., \& McKelvie, A. (2011). The organizational pervasiveness of entrepreneurial orientation. Entrepreneurship Theory and Practice, 35(5), 895-923. https://doi.org/10.1111/j.1540-6520.2011.00451.x

Wiklund, J., \& Shepherd, D. (2005). Entrepreneurial orientation and small business performance: A configurational approach. Journal of Business Venturing, 20(1), 71-91.

https://doi.org/10.1016/j.jbusvent.2004.01.001

\section{Copyrights}

Copyright for this article is retained by the author(s), with first publication rights granted to the journal.

This is an open-access article distributed under the terms and conditions of the Creative Commons Attribution license (http://creativecommons.org/licenses/by/4.0/). 